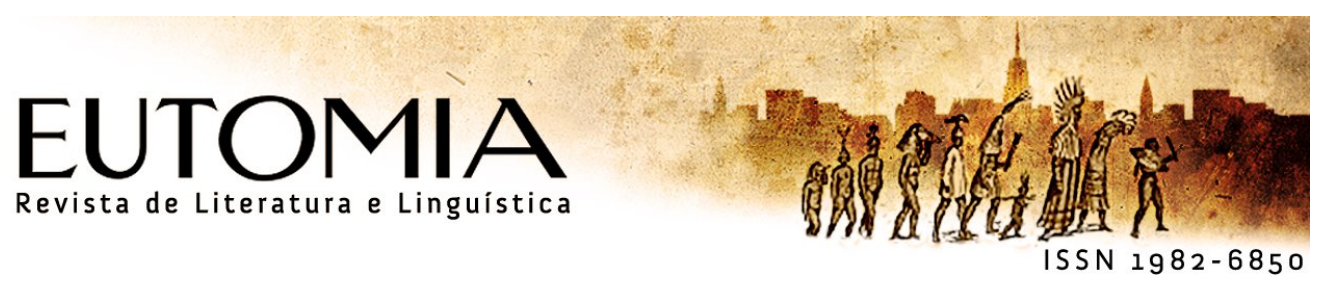

\title{
Leitura e escrita em Projeto Didático de Gênero: o uso de tecnologias e o desenvolvimento das capacidades de linguagem
}

\author{
Dorotea Frank Kerschi (UNISINOS) \\ Renata Garcia Marques ii (UNISINOS)
}

Resumo: Ler e escrever no séc. XXI ultrapassa o limite da palavra impressa. Os desafios que se impõem aos professores são de, nas suas aulas, levar os alunos a ler, escrever e discutir textos multissemióticos. Neste artigo, apresenta-se um Projeto Didático de Gênero desenvolvido com alunos multirrepetentes em escola localizada na periferia de São Leopoldo-RS. Nosso objetivo é mostrar como é possível trabalhar leitura e escrita como práticas sociais, usando tecnologias digitais. Os resultados mostram que, mesmo em escola de periferia, com poucos recursos e sem acesso à internet, foi possível desenvolver as capacidades de linguagem dos alunos, entre elas aquelas necessárias à leitura e produção de textos multimodais.

Palavras-chave: Projeto Didático de Gênero; capacidades de linguagem; leitura e escrita.

\begin{abstract}
Reading and writing in the 21th century overpass the boundaries of the printed word. The challenges that are faced by the teachers, in the classrooms, include inspiring students to read, write and discuss multisemiotic texts. In this article, we present a Genre Didactic Project developed with students that have failed multiple times in a school located on the distressed neighborhood of São Leopoldo -RS. We aim to demonstrate how it is possible to work the reading and writing skills as social practices by using digital technologies. The results show that even in a school from a distressed neighborhood with few resources and no access to the internet, it was possible to improve the students' language skills, including those required to read and produce multimodal texts.
\end{abstract}

Keywords: Genre Didactic Project; laguage skills; reading and writing.

\section{Introdução}

A demanda pelo uso de tecnologias na aula de ensino de língua portuguesa há tempos está presente na vida dos professores. Provavelmente muitos nós tivemos as aulas que demos ou que recebemos enriquecidas com flanelógrafo ou álbum seriado. E quem não recebeu, num passado não muito distante, textos com cheiro de álcool, reproduzidos por 
meio de um mimeógrafo? Também não faz muito tempo que, no lugar do hoje popular ppt, eram produzidas lâminas para serem reproduzidas no retroprojetor. Essas tecnologias, entretanto, não eram acessíveis a todos os professores (talvez alguns tenham precisado pular etapas, dependendo da escola em que atuam/atuavam), muito menos aos alunos, que não interagiam com elas. Os alunos eram obrigados a permanecer passivos diante delas, apenas admirando-as.

Hoje a tecnologia entra na sala de aula por meio dos alunos, mesmo aqueles de comunidades mais afastadas ou localizadas em áreas mais pobres. As facilidades de acesso à internet e o barateamento dos smartphones estão provocando mudanças que talvez nem todos os professores estejam conseguindo acompanhar. E é um pouco disso que nos propomos tratar aqui.

A história deste artigo começa quando uma determinada professora, inquieta, resolve fazer mestrado. A proposta que trouxe para o processo seletivo do PPGLA da Unisinos consistia em ensinar língua portuguesa usando Facebook, mas... detalhe: sua escola não tinha internet, os alunos eram aqueles que haviam ficado à margem: estavam em distorção de idade/série, integravam o projeto "Seguindo em Frente" (que será descrito adiante), viviam em situação de risco, de vulnerabilidade social, tinham muitas dificuldades com a leitura e a escrita.

Além de passar a cursar o Mestrado em Linguística Aplicada, a tal professora (uma das autoras deste artigo) passou a integrar a comunidade de indagação (WELLS, 2006; KERSCH; GUIMARÃES, 2012) do grupo que se reunia todas as terças de manhã para dar conta de um projeto que tinha financiamento do Programa Observatório da Educação da Capes1. Esse projeto tinha entre seus objetivos aproximar reflexões produzidas/em produção em nível acadêmico com o fazer profissional de docentes de Língua Portuguesa para, em um movimento cooperativo, alavancar o desempenho dos alunos no tocante à leitura e escrita como práticas sociais, vistas como pilares de uma educação preocupada com os desafios do futuro que os espera (grifo nosso). É ao que grifamos no objetivo do projeto que este trabalho se alinha.

\footnotetext{
${ }^{1}$ Trata-se do projeto "Por uma formação continuada cooperativa para o desenvolvimento do processo educativo de leitura e produção textual escrita no Ensino Fundamental", aprovado no edital 2010 do Programa Observatório da Educação, coordenado por Ana Maria Mattos Guimarães, do qual uma das autoras era pesquisadora associada, a outra, mestranda bolsista do mesmo Programa. Agradeço à Ana Guimarães, a oportunidade de ter aprendido tanto com ela.
} 
Identificado que a turma em questão apresentava sérios problemas de leitura e escrita, como seria possível alavancar o desempenho desses alunos no tocante à leitura e escrita como práticas sociais? Como desenvolver as capacidades de linguagem desses alunos, preparando-os minimamente para o futuro que os espera? Neste artigo, nos propomos a discutir os resultados do desenvolvimento de Projeto Didático de Gênero - PDG (KERSCH; GUIMARÃES, 2012; GUIMARÃES; KERSCH, 2015) com turmas em distorção de série/idade e mostrar como é possível trabalhar leitura e escrita como práticas sociais, usando tecnologias digitais, mesmo em escola de periferia, com poucos recursos, e, com isso, desenvolver as capacidades de linguagem dos alunos.

Além desta introdução, este trabalho tem quatro partes: a próxima seção traz os fundamentos teóricos que o sustentam - sua vinculação ao Interacionismo Sociodiscursivo e aos Estudos de Letramento, em que o PDG, a metodologia de trabalho do grupo que integramos, se ancora. Na parte seguinte, caracterizamos a turma, e descrevemos o Projeto Didático de Gênero que foi desenvolvido e cada uma de suas etapas. Os resultados já vão sendo discutidos à medida que apresentamos cada etapa do PDG. Por fim, à guisa de conclusão, tecemos algumas considerações, que nunca são finais, e indicamos estudos futuros.

\section{Fundamentação teórica: entre letramentos e ISD}

Se queremos preparar os alunos para o futuro que os espera, cabe perguntar: o que significa, de fato, preparar os alunos para ler e escrever no século XXI? Tomamos a liberdade de parafrasear Daley (2010, p. 482) para responder a essa pergunta: os indivíduos do séc. XXI serão realmente letrados se aprenderem a ler e escrever a linguagem multimidiática da tela. Isso nos coloca novos desafios. Já não podemos ensinar da mesma forma como nós aprendemos. Não basta ensinar a ler e a escrever (a palavra impressa); é preciso desenvolver não só as capacidades de linguagem conforme preconizado por Dolz, Pasquier e Bronckart (1993), Cristóvão e Stutz (2011) e Cristóvão (2013), mas parece que os novos tempos requerem que a escola desenvolva também capacidades que deem conta das multissemioses (ROJ 0, 2009, p. 105), ou seja, todas as formas de criar e produzir significado a partir das "possibilidades multimidiáticas e hipermidiáticas do texto eletrônico" que são trazidas para o ato da leitura. Para Rojo (2009, p. 106), esses textos multissemióticos já 
ultrapassaram os limites dos ambientes digitais, invadindo e impactando também os impressos, como jornais, revistas, livros didáticos.

As mudanças na sociedade e as novas exigências em relação à leitura e à escrita ressignificam os letramentos, que passam a ser vistos como múltiplos. Nesse contexto, a escola precisa criar situações em que os alunos sejam levados a ler e a escrever para fins específicos, não só para a escola, mas também para além dela, e a metodologia do PDG, como veremos adiante, se presta muito a isso. Lemke $(2010$, p. 457) afirma que outrora a escrita requeria caneta e papel ou máquina de datilografia, e a leitura, apenas o livro (e talvez um par de óculos); hoje, todavia, se queremos ler ou produzir um hipertexto, precisaremos praticamente das mesmas tecnologias de hardware e software, e novas habilidades de autoria e de interpretação para usá-las se farão necessárias.

Nosso trabalho se fundamenta numa concepção interativa de linguagem. Leitura e escrita, usadas para agir no mundo, são práticas sociais; são vistas como diálogo entre sujeitos historicamente construídos. Nesse diálogo, os sentidos são firmados, reafirmados, contrapostos, desmentidos (KERSCH; GUIMARÃES, 2012). Para Bronckart (2009), as práticas de linguagem são os principais instrumentos do desenvolvimento humano. 0 autor diz que os gêneros constituem um espaço importante para a aprendizagem social, pois possibilitam ao agente (produtor do texto) ativar mecanismos durante sua produção, bem como o habilitam à adoção e à adaptação do gênero, em uma situação comunicativa:

Para a implementação desses mecanismos, esse agente necessariamente progride em seu conhecimento dos gêneros que são adaptados a uma situação de interação, com um conjunto de restrições linguísticas que lhes são próprias, ao mesmo tempo em que também aprende a gerenciar indexações sociais de que cada gênero é portador; inscrevendo-se, assim, na rede de significações cristalizadas nos modelos preexistentes e aprendendo a se situar em relação a eles. (BRONCKART, 2009, p. 154).

Isso significa que, a partir da interação social, desse gerenciamento de indexações sociais de que cada gênero é portador, é possibilitado ao aprendiz uma apropriação do gênero, uma progressão do seu conhecimento. O gênero, para Schneuwly e Dolz (2004), é um instrumento para agir em situações linguageiras (representa o funcionamento da linguagem); um instrumento cultural (mediador nas interações de indivíduos-objeto); em um instrumento didático (mediador entre as práticas sociais e os objetos escolares). 
Para agir no mundo, escrevemos e falamos textos, materializados em gêneros, que são tipos relativamente estáveis de enunciados que cada esfera de utilização da língua elabora. Essa 'estabilidade relativa' faz com que os gêneros sejam mudar e se adaptar ao processo histórico e social. Um gênero, pois, que circula numa esfera e outra, sofrerá alterações, se adaptará. Lemke (2010, p. 457) afirma que

Aquilo que parece ser o mesmo texto ou gênero multimidiático não é funcionalmente o mesmo quando no papel ou na tela, segue diferentes convenções de significado e requer diferentes habilidades para que seu uso seja bem-sucedido, quando funciona em diferentes redes sociais para diferentes objetivos, como parte de diferentes atividades humanas. Um letramento é sempre um letramento em algum gênero e deve ser definido com respeito aos sistemas sígnicos empregados, às tecnologias materiais usadas e aos contextos sociais de produção, circulação e uso de um gênero particular.

Há hoje uma ideia bastante difundida de que os alunos teriam um bom conhecimento sobre a linguagem da tela. De fato, os alunos navegam com facilidade pelas redes sociais, mais precisamente para "curtir, compartilhar e comentar" conteúdo que circula nas redes sociais. Mas em que medida sabem produzir conhecimento, analisar e escolher criticamente a mídia mais adequada para determinado propósito? Concordamos com Daley (2010, p. 488) quando diz que

eles não têm mais habilidade crítica com essa linguagem do que os mais velhos que eles - talvez menos. Eles precisam aprender a escrever para a tela e a analisar multimídia, tanto, senão mais, do que precisam escrever e analisar qualquer gênero textual específico. Geralmente, tiveram algum tipo de instrução sobre texto no secundário, mas raramente receberam instrução similar para multimídia. A multimídia, tão onipresente na experiência dos jovens, muitas vezes parece particularmente difícil de ser analisada ou desconstruída por eles.

Refletir, pois, sobre os mais variados gêneros (além de lê-los e produzi-los), que circulam nos mais variados espaços da vida social é tarefa da escola, se ela realmente se preocupa em formar cidadãos preparados para agir no mundo. A pesquisa de cujo desenvolvimento vimos participando nos últimos quatro anos originou o que temos denominado Projeto Didático de Gênero - PDG (KERSCH; GUIMARÃES, 2012; GUIMARÃES; KERSCH, 2012, 2014, 2015). Trata-se de uma metodologia de trabalho com ensino de língua(s) preocupada 
não só com o desenvolvimento do(s) letramento(s) aluno, mas também do professor, como mostra a figura abaixo.

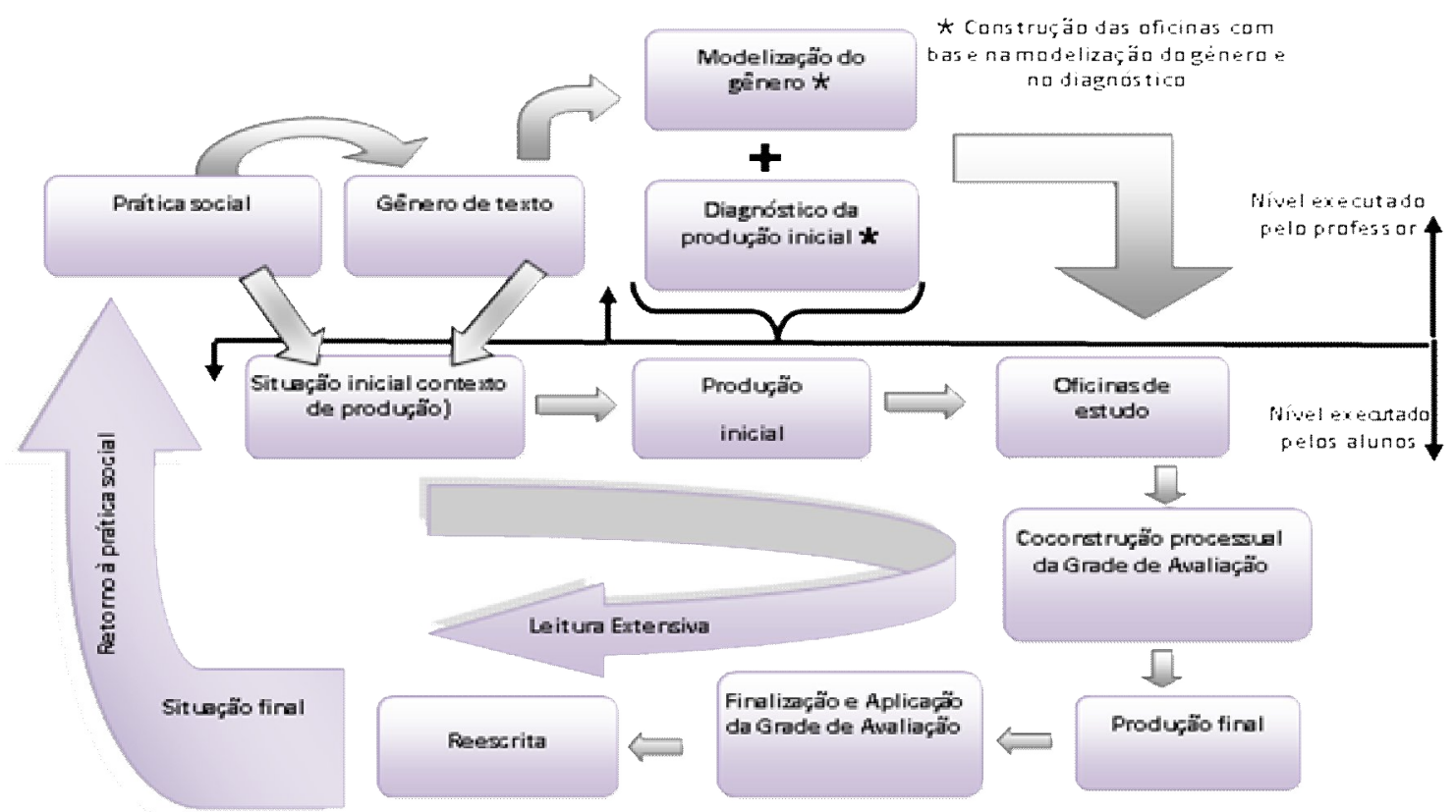

Estrutura do PDG, contemplando os dois níveis de execução - professor e alunos (RABELLO, 2015)

O PDG, como mostra a figura acima, envolve um planejamento do professor, e atividades dos alunos são pensadas a partir das características do gênero e das suas capacidades de linguagem, demonstradas em uma produção inicial (PI), que servirá para diagnóstico e comparação com a reescrita da produção final (PF). Após a reescrita, o gênero vai servir à sua função social.

Com o PDG, didatizam-se os gêneros. Como se trata de um projeto, envolve, como mostra a figura, uma sequência de atividades, realizadas dentro e fora da escola. O PDG, da forma como o concebemos, é uma releitura das sequências didáticas (SCHNEUWLY; DOLZ, 2004), e guarda ainda semelhança delas, no que diz respeito à sistematização do trabalho com o gênero. Recebeu influência também dos Projetos de Letramento (KLEIMAN, 2000) pelo vínculo que tem com a prática social e por nascer de uma demanda que emerge na sala de aula, a que os alunos atenderão. Trata-se, portanto, de um projeto que, a partir da contextualização e produção inicial (PI), engloba uma sequência de atividades (oficinas), para levar os alunos à produção final (PF). Nesse momento, juntamente com os alunos, 0 professor constrói a grade de avaliação, que ajudará o aluno a ser o primeiro avaliador de 
seu texto e fazer a reescrita de seu texto. Após essa etapa, o gênero circula no lugar que lhe é próprio, cumprindo sua função social (a prática social). Por essa razão, esse texto pode circular na escola (jornal escolar, blog, pôster), ou circular fora dela, ganhando o mundo, como é o caso das notícias publicadas no Facebook, como se destaca neste artigo.

Em suma, em projetos dessa natureza, ambos (professor e alunos) se envolvem, ambos são autores, ambos aprendem. É o (novo) educador que a escola brasileira precisa: o professor pesquisador, protagonista, líder e formador de lideranças, como afirmamos em Guimarães e Kersch (2015).

Desenvolver projetos dessa natureza também possibilitam acompanhar 0 desenvolvimento das capacidades de linguagem (CL) dos alunos. 0 conceito de capacidades de linguagem surge no seio das discussões teóricas do ISD. Segundo Bronckart (1999), as condutas humanas são mediadas e organizadas pela linguagem. Nessa perspectiva, a linguagem é uma forma de ação que se realiza por meio do discurso socialmente situado e partilhado. A língua, nesse sentido, não ocorre de forma isolada, mas emerge de uma prática social, se realiza como ação conjunta e partilhada entre os sujeitos, e entre o sujeito e o mundo. Sua manifestação se dá no discurso, que se constrói em contexto social e histórico, por sujeitos reais, que usam a língua para promover as ações de linguagem (convencer, contar caso, dar opinião, relatar, etc).

Seguindo a perspectiva do ISD, as capacidades de linguagem representam um conjunto de conhecimentos de base social, cognitiva e linguística, mobilizados na produção ou recepção do gênero de texto (DOLZ; PASQUIER; BRONCKART, 1993). O domínio dessas capacidades potencializa o sujeito a ser um usuário competente de sua própria língua. A decisão por um determinado gênero de texto, e não outro, e as escolhas linguísticas para sua textualização são decorrentes da capacidade do sujeito de mobilizar, simultaneamente, um conjunto de conhecimentos denominados de capacidades de linguagem.

Assim, ler e produzir textos de diferentes gêneros mobilizam conhecimentos relacionados às capacidades de linguagem, as quais estão ligadas diretamente aos níveis de dificuldade que as operações de linguagem oferecem ao sujeito na materialização de um gênero textual. Conforme Schneuwly e Dolz (2011, p. 44), as CL caracterizam-se por acionar conhecimento, aptidões do aprendiz para a produção de um gênero em uma determinada situação de interação, o que, segundo eles, resulta no desenvolvimento dos três níveis das capacidades de linguagem: as capacidades de ação, as capacidades discursivas e as 
capacidades linguístico-discursivas. No Brasil, a partir das pesquisas realizadas por Cristóvão e Stutz (2011) e Cristóvão (2013), os níveis de capacidades de linguagem são ampliados, acrescentando a capacidade de significação.

A partir dos conceitos de capacidades de linguagem, é possível compreender como 0 sujeito aciona suas capacidades no processo de construção de um gênero, mobiliza mecanismos de operações de linguagem e interação entre os interlocutores na formalização e compreensão de um texto. A elucidação desses conceitos torna esclarecedor o trabalho com os gêneros textuais e o desenvolvimento de propostas didáticas que possibilitam tornar o gênero um instrumento para o ensino da língua materna.

De acordo com Cristóvão (2013), pode-se afirmar que as quatro capacidades de linguagem (de ação, discursiva, linguístico-discursiva e significação) funcionariam como uma "engrenagem", por meio da qual todas as capacidades precisam ser operacionalizadas pelo aprendiz para a produção de um gênero.

As capacidades de ação (CA), conforme Schneuwly e Dolz (2011), exigem que as aptidões requeridas do aprendiz para a produção de um gênero estejam ligadas à representação do contexto social. Ou seja, ele precisará mobilizar capacidades para reconhecer o destinatário, o conteúdo específico, o objetivo específico, a situação comunicativa específica.

As capacidades discursivas (CD), segundo os autores, caracterizam-se por mobilizar modelos discursivos do gênero ligados diretamente à estrutura discursiva do texto.

As capacidades linguístico-discursivas (CLD) representam as unidades linguísticas ou textualização. As operações de textualização (conexão, coesão nominal e verbal), os mecanismos enunciativos de gerenciamento de vozes e a modalização, a construção de enunciados e as escolhas lexicais adequadas ao texto possibilitam ao sujeito gerenciar as operações de linguagem em sua produção textual de forma linear ao conjunto de marcas linguísticas na composição do texto.

As capacidades de significação (CS), de acordo com Cristóvão e Stutz (2011) e Cristóvão (2013) apresentam uma expansão das CL. As CS possibilitam analisar e compreender como o indivíduo interage entre o quadro de intervenção didática para a produção do gênero e a compreensão do texto para construir significados durante 0 agir linguageiro materializado no texto. De acordo com Cristóvão (2013, p. 375), as capacidades de significação estão ligadas e articuladas diretamente às capacidades de linguagem, “[...] 
promovendo o movimento dinâmico e evolutivo da construção do reconhecimento das situações e das possibilidades de agir nessas situações".

Dessa forma, as capacidades de linguagem, enquanto proposta de trabalho pedagógico para o ensino, permitem ao aprendiz mobilizar um conjunto de operações que conduzem à realização de uma determinada ação de linguagem, acionando conhecimentos necessários para a produção daquele gênero. Assim, as capacidades, como um instrumento de ensino, contribuem tanto para o professor (mediador desse processo) quanto para 0 aluno (aprendiz) a compreender o processo da linguagem.

\section{O PDGProfissão Repórter na comunidade e os alunos participantes}

O PDG Profissão Repórter na Comunidade foi desenvolvido em 2013 em uma escola municipal de ensino fundamental completo (São Leopoldo/RS), que, de 2011 a 2014, desenvolveu um trabalho pedagógico com um olhar diferenciado para alunos multirrepetentes, os quais formaram as turmas do Projeto Seguindo em Frente ${ }^{2}$. A multirrepetência é um problema no cenário da educação brasileira, e sua causa pode estar ligada a problemas sociais, à dificuldade de aprendizagem, à baixa autoestima do aprendiz, à indisciplina ou ainda à forma como o professor trabalha, usando metodologias que não atingem, invisibilizam ou mesmo excluem ainda mais esses alunos. 0 fato é que, seja pelo motivo qual for, a multirrepetência precisa receber atenção, o que, entretanto, não cabe neste artigo. Nossa proposta é mostrar como, em um cenário árido como o descrito, formado por apenas alunos em distorção série/idade, o desenvolvimento de um Projeto Didático de Gênero permitiu obter resultados significativos no processo de aprendizagem desses alunos, desde o desenvolvimento de suas capacidades de linguagem para chegar ao letramento digital.

A turma era composta por 25 estudantes com idade entre 15 a 17 anos, multirrepentes de 6a a 7ạ série. Boa parte desses alunos apresentava dificuldade de aprendizagem e baixa autoestima quanto a sua capacidade de aprender os conteúdos

\footnotetext{
${ }^{2} 0$ projeto Seguindo em Frente prevê a aceleração dos estudos de alunos em distorção série/idade. Esse projeto é amparado e orientado pela Lei de Diretrizes e Bases da Educação Nacional (LDBEN) em seu Art. 24, inciso V, alínea B, que aponta para a "[...] possibilidade de aceleração de estudos para alunos com atraso escolar".Esse projeto foi implantado em 2010, resultado de uma parceria entre a Secretaria Municipal de Educação (SMED) de São Leopoldo-RS e algumas escolas da rede municipal de ensino fundamental.
} 
ensinados pelos professores. Além disso, estavam inseridos em uma comunidade que convive com diversos tipos de violência, atingindo, de alguma forma, a perspectiva de vida desses jovens e provocando desinteresse pela escola. A escola, cujo corpo docente é constituído de 80 professores, tem aproximadamente 1400 alunos e está localizada em um dos bairros periféricos do município de São Leopoldo-RS. Conta com uma sala de recursos para alunos especiais, biblioteca, auditório (150 pessoas), refeitório, dois laboratórios de informática. Na época, a escola não tinha acesso à internet ${ }^{3}$. Isso, entretanto, não foi impeditivo para o desenvolvimento de um PDG, que requeria o uso de tecnologia.

Diante da dificuldade de leitura e de escrita desses alunos, optou-se pelo gênero notícia, por se considerar que esse gênero está presente na vida dos cidadãos de um modo geral, atingindo esses alunos também. As ações da comunidade circulam na mídia na forma de notícias. Além disso, há uma estreita relação do curso de Jornalismo da Universidade do Vale do rio dos Sinos - Unisinos com a comunidade do bairro a que os alunos pertencem, envolvendo-a com um jornal experimental que os alunos da universidade produzem.

A circulação do gênero notícia em rádio, na TV, com noticiários e jornais televisivos (locais e nacionais); em jornais e revistas impressas, sites de jornais e revistas, e algumas delas recebem destaque se compartilhadas pelas redes sociais. Enfim, os gêneros que pertencem ao âmbito jornalístico atingem a grande massa de diversas formas. Em função da relação direta da comunidade com o J ornal Enfoque ${ }^{4}$, o que evidencia uma prática social: a leitura de notícias sobre a própria comunidade está no cotidiano dos alunos e suas famílias. Portanto, o estudo do gênero notícia, presente na prática social desses alunos, em nossa avaliação, poderia contribuir muito para aprimorar e ampliar o seu processo de escrita e leitura, tornando-os mais autônomos em sua aprendizagem.

Seguindo a perspectiva preconizada por Kersch e Guimarães $(2011,2012)$ e Guimarães e Kersch (2015), após conhecer alunos e comunidade, identificada a prática social, foi elaborado um PDG com 24 oficinas, totalizando 29 atividades, conforme resumido abaixo.

\footnotetext{
${ }^{3}$ Diante do problema da falta de internet, a professora solucionou com outro recurso (Moden - Internet 3G dela e dos alunos que também possuíam a internet 3G e notebook) nas aulas de Língua Portuguesa ministradas no Laboratório de Informática e na sala de aula.

${ }^{4}$ O J ornal Enfoque é um jornal comunitário e, há 10 anos, é produzido pelo curso de Jornalismo da Unisinos, e tem como foco produzir notícias, entrevistas, reportagens e outros gêneros do âmbito jornalístico sobre essa comunidade local, que aprecia muito esse jornal comunitário, que é distribuído gratuitamente para os moradores do bairro.
} 


\begin{tabular}{|c|c|c|}
\hline & Oficinas & Resumo das atividades desenvolvidas \\
\hline \multirow{3}{*}{$\begin{array}{l}\text { Primeira } \\
\text { etapa: } \\
\text { Compreen- } \\
\text { dere } \\
\text { estudaro } \\
\text { gênero } \\
\text { notícia }\end{array}$} & Oficina 1 & $\begin{array}{l}\text { Apresentação do PDG: começando uma nova proposta } \\
\text { Produção inicial }\end{array}$ \\
\hline & Oficina 2 & Estudo dos gêneros notícia e entrevista \\
\hline & Oficina 3 & $\begin{array}{l}\text { Leitura e estudo dos gêneros notícia e entrevista no Jornal } \\
\text { Enfoque }\end{array}$ \\
\hline \multirow{6}{*}{$\begin{array}{c}\text { Segunda } \\
\text { etapa: } \\
\text { Iniciar as } \\
\text { atividades } \\
\text { linguísticas } \\
\text { do gênero } \\
\text { notícia }\end{array}$} & Oficina 4 & $\begin{array}{l}\text { Discussão e atividades sobre as dificuldades ortográficas dos } \\
\text { aprendizes }\end{array}$ \\
\hline & Oficina 5 & A pontuação e o desenvolvimento de atividades linguísticas \\
\hline & Oficina 6 & $\begin{array}{l}\text { Da teoria à prática da notícia - produção de uma notícia sobre o } \\
\text { aniversário da escola (Evento) }\end{array}$ \\
\hline & Oficina 7 & Os tempos verbais e mais atividades linguísticas \\
\hline & Oficina 8 & $\begin{array}{l}\text { Referenciação e estudo de pronomes - Ampliando } 0 \\
\text { conhecimento linguístico }\end{array}$ \\
\hline & Oficina 9 & $\begin{array}{l}\text { Desafio: Produzindo coerência na produção de uma notícia em } \\
\text { grupo! }\end{array}$ \\
\hline \multirow{2}{*}{$\begin{array}{c}\text { Terceira } \\
\text { etapa: } \\
\text { Seminário } \\
\text { na } \\
\text { Universida } \\
\text { de } \\
\text { Unisinos } \\
\end{array}$} & Oficina 10 & $\begin{array}{l}\text { Novos horizontes - Seminário na Universidade Unisinos: Gêneros } \\
\text { textuais no âmbito jornalístico (08 horas de curso com estudantes } \\
\text { do jornalismo) }\end{array}$ \\
\hline & Oficina 11 & $\begin{array}{l}\text { Debate sobre a experiência no Seminário na Unisinos- novas } \\
\text { estratégias para a elaboração das notícias }\end{array}$ \\
\hline \multirow{6}{*}{$\begin{array}{l}\text { Quarta } \\
\text { etapa: } \\
\text { Produzir a } \\
\text { notícia! }\end{array}$} & Oficina 12 & $\begin{array}{l}\text { Reflexão sobre o tema da PI e elaboração das perguntas para } \\
\text { realizar a entrevista - Praticando a teoria }\end{array}$ \\
\hline & Oficina 13 & Orientação para realizar a entrevista presencial (oralidade) \\
\hline & Oficina 14 & Da teoria à prática - A Entrevista presencial \\
\hline & Oficina 15 & O grande momento - A produção final \\
\hline & $\begin{array}{l}\text { Oficina } \\
16\end{array}$ & Coconstrução da grade de avaliação - Retomando conceitos \\
\hline & Oficina 17 & O produto final - A Notícia \\
\hline
\end{tabular}




\begin{tabular}{|c|l|l|}
\hline \multirow{2}{*}{$\begin{array}{c}\text { Quinta } \\
\text { etapa: }\end{array}$} & Oficina 18 & Debate sobre a importância de publicar as notícias na rede social \\
e supostos interlocutores
\end{tabular}

(MARQUES, 2014)

Para análise, neste artigo, vamos apresentar resumidamente o PDG Profissão Repórter na Comunidade, dividido em contextualização, mais cinco etapas e, para compreender como, por meio do PDG, foi possível desenvolver as capacidades de linguagem dos alunos, discutiremos um texto multissemiótico, do aluno Pedro ${ }^{5}$ publicado no grupo fechado criado pela professora no Facebook. O texto de Pedro não se resumia ao texto escrito, como veremos adiante.

Na proposta de PDG, como se disse antes, o professor parte da contextualização, chamando a atenção dos alunos de que o gênero textual proposto (oral ou escrito) precisa estar vinculado a uma situação de comunicação real (ou muito próxima da realidade) e atender a uma prática social dos alunos. Dessa forma, no PDG descrito, a proposta é inserir os alunos em uma situação comunicativa em que eles escrevam uma notícia sobre e para a comunidade local e escolar, e os textos serão lidos por essas comunidades no Jornal Enfoque e no ambiente virtual (Facebook).

\section{Primeira etapa: Compreender e estudar os gêneros notícia e entrevista}

As operações de linguagem desenvolvidas nas 03 oficinas (compostas por seis atividades) desta primeira etapa serviram de instrumento para conduzir os alunos a

\footnotetext{
${ }^{5}$ Por questões éticas, vamos preservar o nome do aluno.
} 
mobilizar suas capacidades de linguagem e reconhecer, principalmente, a estrutura discursiva do gênero notícia e, de forma secundária, o gênero entrevista, o qual não será explorado como uma produção textual, mas como um recurso (a fonte, a fala do entrevistado) usado na composição do gênero notícia. A maioria das atividades propostas visa a mobilizar e movimentar, de forma circular, as quatro capacidades de linguagem do aprendiz, entretanto elas não ocorrem na mesma proporção. Embora as quatro capacidades estejam presentes em quase todos os exercícios, as capacidades de ação e discursivas, nessas oficinas, são as mais exploradas, pois o objetivo é colocar o aluno em contato principalmente com a notícia, levando-o a compreender determinadas situações comunicativas em que esse gênero ocorre e como é estruturado discursivamente, priorizando atividades ligadas à planificação textual do gênero. As capacidades linguísticodiscursivas não ganham ênfase nessas atividades, pois as atividades se centram em analisar e compreender a composição estrutural do gênero.

As capacidades de significação estão ligadas diretamente às $C A$ e $C D$ e às relações de sentido que 0 aprendiz realiza para compreender o gênero notícia. As oficinas visam a esclarecer o comportamento discursivo que o gênero notícia exige que sujeito produtor adote. Assim, as capacidades discursivas ganham maior ênfase nessa etapa do PDG. De acordo com Cristóvão e Stutz (2011), ao mobilizar as capacidades discursivas, o aprendiz passa a entender a função de organização do conteúdo de determinado gênero, o layout, e a perceber a diferença entre as formas de organização desses conteúdos. Dessa maneira, ao propor as atividades de ler e analisar a constituição dos gêneros notícia e entrevista, as capacidades de linguagem dos alunos são ativadas e desenvolvidas no reconhecimento discursivo desses gêneros. 0 grau de apropriação de cada aprendiz dos gêneros é individual, ligado à capacidade de significação que consegue desenvolver em relação à estrutura do gênero.

\section{Segunda etapa: Iniciar as atividades linguísticas do gênero notícia}

A PI é uma ferramenta para o professor diagnosticar as maiores dificuldades de aprendizagem dos alunos para produzir um gênero. A partir do diagnóstico realizado na PI e o estudo realizado sobre o Modelo Didático de Gênero Notícia, foram desenvolvidas as 06 oficinas (09 atividades linguísticas) nesta segunda etapa. As oficinas de análise linguística 
deram continuidade aos estudos realizados na primeira etapa do PDG. Entretanto, as operações de linguagem, na segunda etapa do PDG, tiveram como foco mobilizar e potencializar especificamente as capacidades linguístico-discursivas dos alunos, pontuando problemas de aprendizagem diagnosticados na PI. Assim, a movimentação de todas as $\mathrm{CL}$ não ocorreu de maneira simultânea, houve uma valorização das CLD, CD, CS, pois as atividades de ortografia e pontuação (lacuna na aprendizagem desses alunos) ganharam ênfase para o estudo de regras gramaticais. Já o estudo dos demais aspectos linguísticos tempos verbais, elementos articuladores, referentes textuais (anáforas), exploração do léxico do gênero notícia, uso da 3a pessoa, incluindo novamente a pontuação - ocorreram de forma contextualizada, proporcionando acionar as capacidades discursivas e linguísticodiscursivas dos alunos, pois os exercícios foram dirigidos à notícia, levando-os a refletir sobre a estrutura do gênero e a relacioná-la às atividades linguísticas. As capacidades de ação foram acionadas nas oficinas que promoveram atividades de produção escrita individual, digitação e apresentação de uma notícia sobre o aniversário da escola; a produção de uma notícia em grupo; e estudo dos tempos verbais recorrentes nesse gênero. Nessas atividades de produção escrita, as quatro capacidades de linguagem estavam presentes, pois exigiram que o aluno repensasse, mais uma vez, a situação comunicativa em que o gênero seria produzido (CA), e colocasse em prática os estudos linguísticos (CLD) e discursivos realizados (CD) sobre o gênero notícia. Além disso, as capacidades de significação foram acionadas, articulando as demais capacidades à medida que os alunos foram se apropriando dos estudos realizados. De acordo com a linha teórica do ISD, "[...] é através dos gêneros que as práticas de linguagem materializam-se nas atividades dos aprendizes" (SCHNEUWLY; DOLZ, 2011, p. 63). Ou seja, o gênero notícia foi usado como um instrumento de reflexão e estudo sobre a língua materna, acionando as capacidades de linguagem dos aprendizes, retomando os conteúdos estudados.

\section{Terceira etapa: Seminário na UNISINOS}

A terceira etapa está vinculada diretamente à prática social do projeto, que visava à publicação de notícias produzidas pelos alunos no Jornal Enfoque. Essa etapa dá continuidade ao trabalho desenvolvido nas etapas anteriores, pois o Seminário Gêneros textuais no âmbitojornalístico possibilitou aos alunos acionar novamente suas capacidades de linguagem e ampliar seu processo de aprendizagem sequencialmente sobre 
o gênero notícia, uma vez que retomou conceitos sobre os gêneros estudados (notícia e entrevista) e possibilitou a discussão de estratégias para os alunos produzirem suas notícias.

o seminário, oferecido na Unisinos, contou com a participação do professor/coordenador do J ornal Enfoque e oito alunos formandos do curso de J ornalismo. Teve duração de oito horas e foi divido em dois momentos. 0 primeiro foi teórico e priorizou o debate sobre o conceito e a estrutura básica dos gêneros notícia, reportagem e entrevista; a leitura, análise e debate sobre o processo de construção de cinco notícias veiculadas em diferentes jornais; a ética e a impessoalidade na produção de textos jornalísticos; o processo de construção e objetivo do Jornal Enfoque; e técnicas para usar as ferramentas midiáticas (sites, blogs, vídeos e imagens) na produção e edição de textos jornalísticos.

No segundo momento do Seminário, novamente todas as capacidades foram acionadas, principalmente as capacidades de ação, discursivas e linguístico-discursivas. Os alunos, divididos em cinco grupos, leram sua PI e dialogaram com os alunos de jornalismo como aquele texto inicial (PI) poderia se tornar uma notícia real. Individualmente, cada aluno recebeu uma orientação do ministrante com sugestões e estratégias para realmente transformar a PI em uma notícia. Ao reconhecer que sua PI não era uma notícia, suas capacidades discursivas (organização do conteúdo) e linguístico-discursivas (operações e recursos de linguagem) foram acionadas, pois a estrutura do gênero e os recursos linguísticos apresentados na PI evidenciavam seu distanciamento do gênero. Os alunos, ao participarem desse evento, puderam refletir e criar novas estratégias para produzir suas notícias, acionando as quatro capacidades.

E, para concluir a terceira etapa, na escola, os alunos receberam um questionário com oito questões para relatar a experiência de terem participado do Seminário na Unisinos. Nele, os alunos registraram suas reflexões, quais seriam as suas ações estratégicas para transformar a PI em uma notícia. Novamente, ao responder as questões e registrá-las, os alunos foram conduzidos a acionar suas capacidades de ação (situação de comunicação), discursivas (estrutura do gênero), linguístico-discursivas (operações de linguagem) e significação (texto e contexto) em relação ao processo de construção para escrever a sua notícia. 


\section{Q uarta etapa: Produzir a notícia!}

A quarta etapa do PDG é o fechamento da produção do gênero notícia e foi dividida em seis oficinas. Em todas as oficinas, exceto na oficina 13, as atividades propiciaram 0 desenvolvimento das quatro capacidades de linguagem. Entretanto, em cada oficina, algumas capacidades ganharam mais ênfase que outras, conforme a proposta da atividade, mas todos os exercícios focaram-se diretamente na produção do gênero notícia.

Merecem uma atenção especial as oficinas 12, 14 e 16. Na oficina 12, todas as capacidades de linguagem são acionadas, visto que o aluno deveria produzir cinco questões para cada fonte (entrevistado), e levar em consideração o contexto social, realizando inferências sobre a situação comunicativa (temática, interlocutores, contexto social e objetivo da notícia) para formular as perguntas das entrevistas (CA,CD,CLD,CS) que seriam usadas como depoimentos (entrevistas) para dar veracidade ao seu texto. Essa oficina permitiu-Ihes pensar estratégias para produzir a notícia

Na oficina 14, novamente as quatro capacidades são acionadas no momento em que 0 aluno vivencia e realiza a entrevista presencialmente, com o objetivo de coletar dados para produzir a notícia. Na oficina 15, ele, após todo o estudo realizado ao longo do PDG, escreve a sua notícia (PF). E na oficina 16 , as operações de linguagem realizadas conduziram os alunos a ativarem novamente as quatro capacidades de linguagem em relação ao gênero estudado. A atividade teve como meta construir uma grade de avaliação para orientá-los a reescrever o seu texto (Produção Final). Para isso, a professora propôs a análise de uma notícia em conjunto, solicitando que os alunos destacassem, oralmente, todos os elementos estudados que reconheciam ao ler aquela notícia, anotando as observações na lousa. 


\begin{tabular}{|c|c|c|c|c|}
\hline $\begin{array}{l}\text { GRADE DE AVALIAÇÃO. APÓS TODAS AS ETAPAS ESTU } \\
\text { NOTÍCIA, VERIFIQUE SEU TEXTO E MARQUE UM X NA RE } \\
\text { À SUA PRODUÇÃO FINAL. } \\
\text { Sim }=5 \text { pontos Não=0 pontos Em parte }=3 \text { pontos }\end{array}$ & $\begin{array}{l}\text { JDAD } \\
\text { ESPO }\end{array}$ & $\begin{array}{l}\text { AS S } \\
\text { STA }\end{array}$ & BRE 0 & $\begin{array}{l}\text { GÊNERO } \\
\text { EQUADA }\end{array}$ \\
\hline & SIM & NÃo & $\begin{array}{c}\text { EM } \\
\text { PARTE }\end{array}$ & $\begin{array}{l}\text { O que } \\
\text { faltou? }\end{array}$ \\
\hline 1) 0 seu texto apresenta a estrutura do gênero notícia? & & & & \\
\hline 2) Você utilizou fatos reais para produzir sua notícia? & & & & \\
\hline $\begin{array}{l}\text { 3) Você coletou, no mínimo, duas fontes (entrevistas, dados) } \\
\text { diferentes para elaborar sua notícia? }\end{array}$ & & & & \\
\hline $\begin{array}{l}\text { 4) A sua notícia cumpre uma função social para o contexto onde } \\
\text { será publicada? }\end{array}$ & & & & \\
\hline $\begin{array}{l}\text { 5) } 0 \text { seu texto obedece à estrutura: título (manchete), } \\
\text { apresentação, lide (pequeno resumo da notícia) e corpo do } \\
\text { texto? }\end{array}$ & & & & \\
\hline 6) Você utilizou a linguagem jornalística em sua notícia? & & & & \\
\hline 7) A manchete usada em seu texto é curta e objetiva? & & & & \\
\hline $\begin{array}{l}\text { 8) As seis perguntas básicas ( O quê? Quem? Quando? Onde? } \\
\text { Por quê? Como?), que uma notícia precisa informar ao seu leitor, } \\
\text { foram respondidas em sua notícia? }\end{array}$ & & & & \\
\hline $\begin{array}{l}\text { 9) Em sua notícia, há presença da opinião do repórter em }{ }^{1} \text { a } \\
\text { pessoa? }\end{array}$ & & & & \\
\hline $\begin{array}{l}\text { 10) Em sua notícia, há presença da opinião do(s) entrevistado(s) } \\
\text { em 1a pessoa? }\end{array}$ & & & & \\
\hline $\begin{array}{l}\text { 11)Sua notícia está escrita em } 3^{a} \text { pessoa , e apenas as entrevistas } \\
\text { em 1a pessoa (se for o caso)? }\end{array}$ & & & & \\
\hline $\begin{array}{l}\text { 12) É possível perceber, em seu texto, as estratégias usadas pelo } \\
\text { repórter para escrever e comprovar a veracidade dos fatos da } \\
\text { notícia? }\end{array}$ & & & & \\
\hline $\begin{array}{l}\text { 13) Você utilizou os verbos de forma coerente? Há predomínio } \\
\text { dos verbos no presente do indicativo? }\end{array}$ & & & & \\
\hline
\end{tabular}




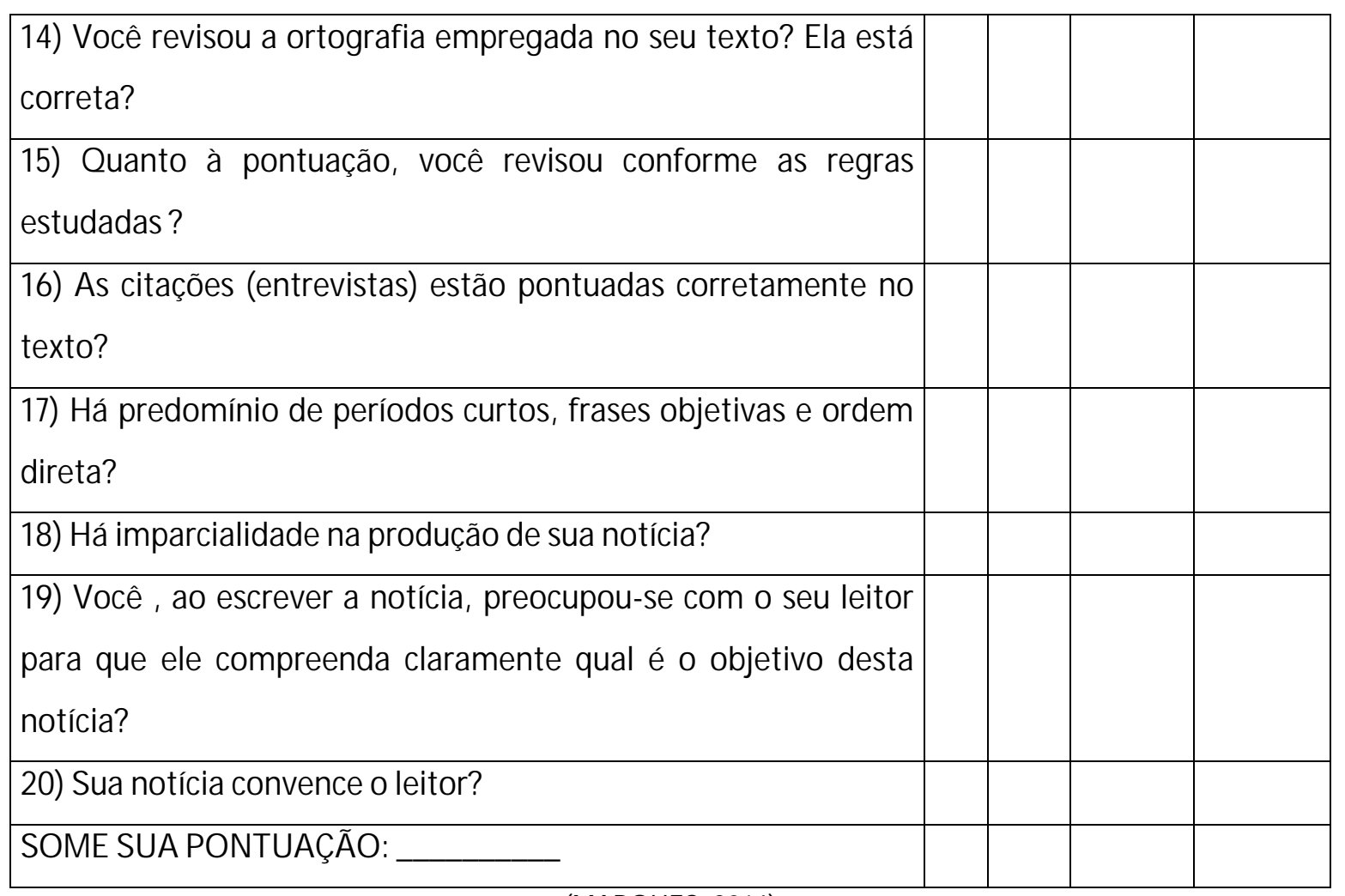

(MARQUES, 2014)

A grade de avaliação construída conjuntamente pela turma e pela professora teve como resultado uma síntese do que caracteriza o gênero notícia, englobando a situação comunicativa (CA) em que o gênero ocorre, a estrutura discursiva (CD), os recursos linguísticos (CLD) recorrentes empregados na produção de uma notícia, e as relações de sentido expressas pelos alunos para a produção do gênero (CS). As capacidades de linguagem na grade foram acionadas ora de forma individual, ora de forma conjunta. Observa-se que as CD e CLD ganharam maior importância na grade de avaliação, pois há uma preocupação tanto da professora quanto da turma para reconhecer o modelo discursivo do gênero notícia.

\section{Quinta etapa: 0 gênero notícia em ação: interação entre alunos e professores na rede social Facebook}

A análise da quinta etapa merece uma atenção especial neste artigo, pois ela aponta como não só as quatro capacidades estão presentes em todas as etapas deste projeto como também a necessidade do uso das tecnologias relacionado diretamente com a aprendizagem do gênero em estudo, a notícia. Essa etapa privilegiou o letramento digital 
dos alunos, permitindo-Ihes aprender a usar determinadas ferramentas midiáticas como máquina digital, celular, gravações de vídeo, editor de textos e de vídeos, internet, interação em ambiente virtual (Facebook) para a composição do gênero notícia e sua posterior publicação. Com a produção para esse fim específico, foi possível valorizar todo 0 processo de leitura e escrita do gênero desenvolvido no PDG, para veiculá-lo em uma rede social, e a comunidade escolar pudesse assistir aos vídeos associados às notícias, lê-las e participar, efetivamente, do projeto dos alunos (curtindo, compartilhando, comentando). No quadro abaixo (p.403), procuramos ilustrar um pouco do que aconteceu, exemplificando com a notícia que Pedro produziu.

Pedro decide tornar a construção de um novo loteamento próximo à escola uma notícia. Para chegar ao texto que pode ser visualizado aqui (e no Facebook), passou por todas as etapas antes mencionadas. Como o lugar de circulação da notícia permitia, Pedro produziu um vídeo, mostrando os impactos desse novo loteamento para a comunidade. Ele não escreveu para a professora corrigir, mas para quem teve acesso ao grupo que, na época, era fechado. Assim, sua matéria recebeu comentários e críticas, inclusive do jornalista que era supervisor de redação do Jornal Enfoque. Ele destaca que em uma notícia sempre se tem de ouvir o outro lado. Continuando a prática social de publicar material em uma rede social (curtir, comentar, compartilhar), a professora toma a palavra, dizendo que o contato com a prefeitura fora feito, mas não obtiveram resposta. Por falta de espaço, não podemos nos estender na análise, mas cremos que pudemos demonstrar as possibilidades que se abrem quando, na escola, se resolve ensinar a ler e escrever "de verdade", ler e escrever como prática social.

Pedro, assim como seus colegas (cada um no seu processo de aprendizagem), ao longo do desenvolvimento do PDG Profissão Repórter na Comunidade, produziu uma notícia, mobilizou e aprimorou suas quatro capacidades de forma significativa em relação à produção do gênero. Entretanto, pensando nas capacidades desenvolvidas neste PDG, parece-nos que pode haver questões no trabalho de Pedro, que foram mobilizadas para ele publicar sua notícia, que não estão contempladas nas quatro capacidades já conhecidas. Pedro construiu um texto multimodal (produção de um vídeo com imagens e textos), que não só ilustra a notícia, mas faz parte dela. Escolheu uma música que achou adequada para divulgar as imagens que fizera. Talvez se fizesse necessário verificar em que medida, Pedro mobilizou capacidades multimodais ou multissemióticas. Do mesmo modo, ainda que os 
alunos tenham algumas dessas capacidades, com certeza a escola tem muito a ensinar (e a aprender) em relação aos letramentos, também os digitais, multissemióticos. Mas isso ainda precisamos investigar melhor e ficará para outro artigo.

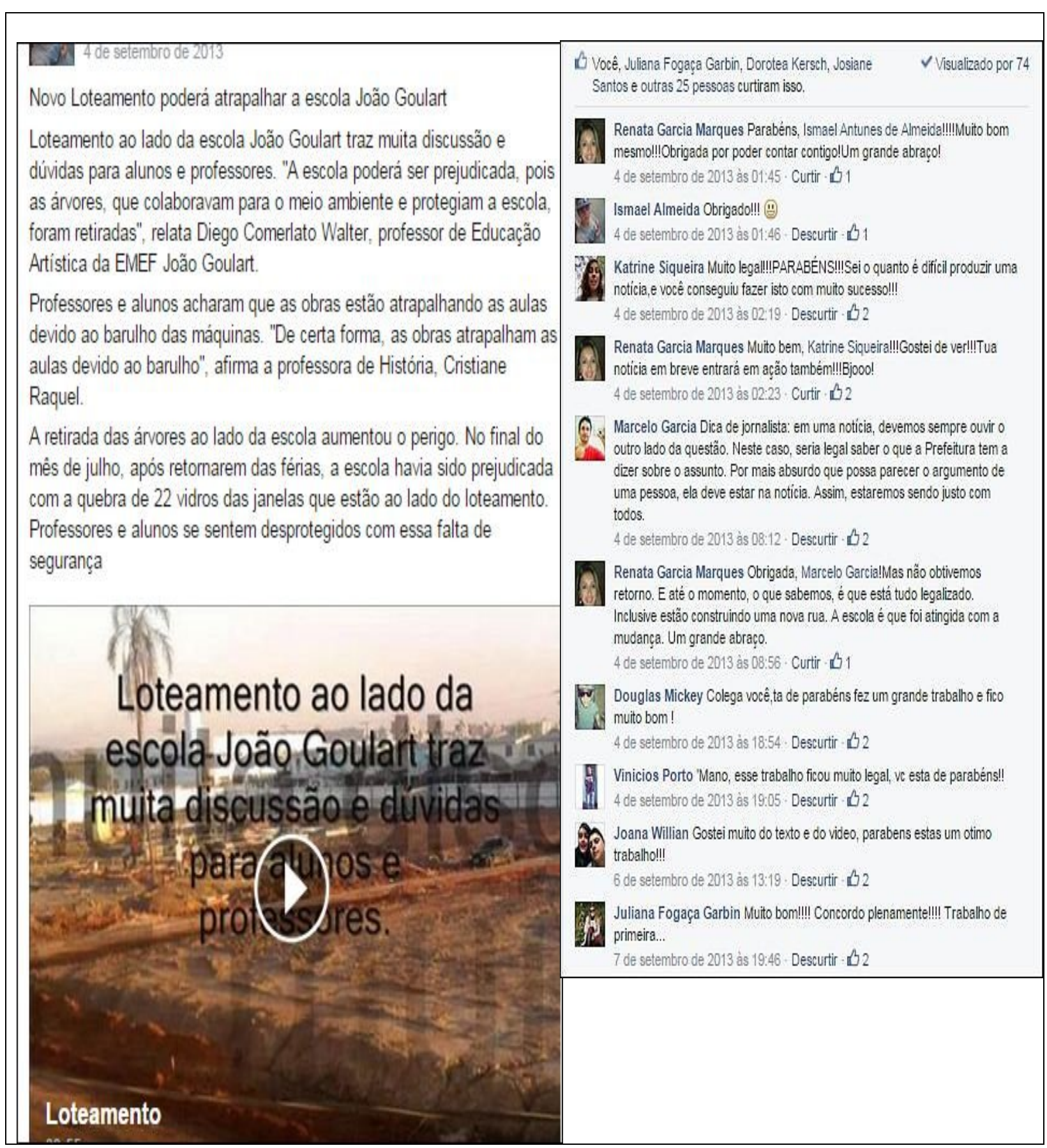




\section{Considerações (nunca finais)}

A tecnologia como recurso didático sempre esteve na vida do professor, entretanto, a forma como cada vez mais as TICS estão presentes na vida dos alunos pressiona o professor a fazer uso delas na sala de aula. Evidentemente, planejar uma aula que requeira 0 uso de tecnologias sempre requereu esforço e trabalho por parte do professor (e vai continuar requerendo).

Não basta deixar a tecnologia entrar na sala de aula, a aprendizagem é situada; é preciso, pois, se fazer a pergunta: por que estou usando esta tecnologia com estes alunos? Se tivermos clareza na resposta a essa pergunta, daremos conta de uma aprendizagem de leitura e escrita como prática social. Como foi possível analisar, a proposta metodológica de PDG conduz o professor a desenvolver um projeto que tenha como meta ensinar e vincular o gênero textual a uma prática social, assim como explorar e ensinar a usar os recursos linguísticos (e tecnológicos, se necessário) para a formalização do texto, promovendo um espaço para o aprendiz se apropriar de uma prática de linguagem e desenvolver suas quatro capacidades. E os professores que têm trabalhado com PDGs tem nos mostrado inúmeras formas de fazer isso, inclusive, em como trabalhar de forma interdisciplinar (RABELLO, 2015), ou em como integrar a tecnologia, mesmo em uma escola de periferia, que carece de recursos que parecem essenciais, como conexão à internet.

Parece-nos que a preocupação com o fantasma dos conteúdos que assombra os professores é sem sentido, porque, como vimos, é possível, sim, integrar conteúdos ao projeto (mas com uma gramática "útil", contextualizada, a gramática que o gênero em estudo necessita).

Por fim, cabe destacar que a leitura e a escrita, tanto no impresso quanto no digital, são atividades dinâmicas que requerem sistematização, ensino, acompanhamento, fazendo professor e alunos interagirem com o texto, seja ela impresso ou digital (vimos isso na repercussão que o texto de Pedro causou: ele foi elogiado, recebeu críticas e sugestões, todos em 'atitude responsiva ativa'). Essa perspectiva de trabalho, em que todos se envolvem, encorajará os alunos a interagirem com os colegas, ensinando-os a conviver com a diferença (de pensamento, cultural, étnica, linguística etc), construindo uma sala de aula mais democrática em que, inclusive aqueles desacreditados, como Pedro, possam se pronunciar e ver/ouvir sua voz ecoando. 


\section{Referências}

BRONCKART, J.-P. Atividade de linguagem textos e discursos: por um interacionismo sóciodiscursivo. São Paulo: EDUC, 1999.

BRONCKART, J.-P. Atividade de linguagem, textos e discursos: por um interacionismo sociodiscursivo. 2.ed. São Paulo: EDUC, 2009.

CRISTÓVÃO, Vera Lúcia Cristóvão. Para uma expansão do conceito de capacidades de linguagem. In: BUENO, Maria Angela; LOPES, Paulino Teixeira; CRISTÓVÃO, Vera Lúcia Lopes (Org.). Gêneros textuais e formação inicial: uma homenagem à Malu Matencio.Campinas: Mercado de Letras. 2013. p. 357-383.

CRISTÓVÃO, Vera Lúcia; STUTZ, Lídia. Sequências didáticas: semelhanças e especificidades no conteúdo francófono como Lle no contexto brasileiro como LE. In: Szundy, P.T.C.; Araújo, J. C.; Nicolaides, C. S; SILVA, R. A. (orgs.). Linguística aplicada e sociedade: ensino e aprendizagem de línguas no contexto brasileiro.Campinas: Pontes Editores, 2011, v1, p.17-40.

DALEY, Elizabeth. Expandindo o conceito de letramento. Trab. linguist. apl., Campinas, v. 49, n. 2, p. 481-491, Dec. 2010. Disponível em «ttp://www.scielo.br/scielo.php?script=sci_arttext\&pid $=\$ 0103-$ $18132010000200010 \& \operatorname{lng}=e n \& n r m=$ iso $>$. access on 10 Julho 2015. http://dx.doi.org/10.1590/S0103-18132010000200010.

DOLZ, J.; PASQUIER, A.; BRONCKART, J ean-Paul. "L'acquisition des discours: emergence d'une competence ou apprentissage de capacities langagières?" ĖLA - Études de Linguistique Appliquée, 1993, no 92, pp. 23-37.

GUIMARÃES, A. M. M.; KERSCH, D. F.. (orgs.). Caminhos da construção: projetos didáticos de gênero na sala de aula de língua portuguesa. Campinas, SP: Mercado de Letras, 2012.

GUIMARÃES; A. M. M.; KERSCH, D. F.(orgs). Caminhos da construção: projetos didáticos de gênero no domínio do argumentar. Campinas, SP: Mercado de Letras, 2014. -- (Série Caminhos da Construção)

GUIMARÃES; A. M. M.; KERSCH, D. F.(orgs). Caminhos da construção: reflexões sobre projetos didáticos de gênero.Campinas, SP: Mercado de Letras, 2014. -- (Série Caminhos da Construção)

KERSCH, D. F. ; GUIMARÃES, A. M. M. . Por uma formação continuada cooperativa: 0 desenvolvimento do processo educativo de leitura e produção textual escrita no ensino fundamental no contexto de um município brasileiro. In: VI SIGET - Simpósio Internacional de Estudos de Gêneros Textuais, 2011, Anais,Natal. VI SIGET/ANAIS, 2011.

KERSCH, D. F. ; GUIMARÃES, A. M. M. A construção de projetos didáticos de leitura e escrita como resultado de uma proposta de formação continuada cooperativa. Revista Brasileira de Linguística Aplicada, v. 12, p. 533-556, 2012 
KLEIMAN, Angela B. 0 processo de aculturação pela escrita: ensino da forma ou aprendizagem da função? In: KLEIMAN, Angela B.; SIGNORINI, I. (Orgs.) 0 ensino e a formação do professor. Alfabetização de jovens e adultos. Porto Alegre: Artmed, 2000. 248 p. p. 223-243.

LEMKE, J ay L.. Letramento metamidiático: transformando significados e mídias. Trab. linguist. apl., Campinas, v. 49, n. 2, p. 455-479, Dec. 2010. Disponível em বttp://www.scielo.br/scielo.php?script=sci_arttext\&pid=\$0103$18132010000200009 \&$ Ing =en\&nrm=iso $>$. acesso em 10 Jul 2015. http://dx.doi.org/10.1590/S0103-18132010000200009.

MARQUES, R. G. Projeto didático de gênero como possibilidade para o ensino da língua materna e o desenvolvimento das capacidades de linguagem de alunos multirrepetentes. 2014. Dissertação (Mestrado em Linguística Aplicada) - Universidade do Vale do Rio dos Sinos, Coordenação de Aperfeiçoamento de Pessoal de Nível Superior. Orientador: Dorotea Frank Kersch.

RABELLO, K. R. O uso de artigos midiáticos de divulgação científica em um Projeto Didático de Gênero: uma proposta para construção do aprendizado interdisciplinar em sala de aula.2014. Dissertação (Mestrado em Linguística Aplicada) - Universidade do Vale do Rio dos Sinos, Coordenação de Aperfeiçoamento de Pessoal de Nível Superior. Orientador: Dorotea Frank Kersch.

ROJ O, Roxane. Letramentos múltiplos, escola e inclusão social, São Paulo: Parábola Editorial, 2009

SCHNEUWLY, B. \& DOLZ, J. Os gêneros escolares - das práticas de linguagem aos objetos de ensino. In: SCHNEUWLY, B. \& DOLZ, J. et al. Gêneros orais e escritos na escola. Campinas: Mercado de Letras, 2004, p. 71-91

SCHNEUWLY, Bernard; DOLZ, J oaquim. Gêneros orais e escritos na escola. 3. ed. Campinas: Mercados das Letras, 2011.

WELLS, G. La unión de las dimensiones sociales, intelectuales y afectivas de la educación para transformar la sociedad. In: ALCALDE, A. I. et al. Transformando la escuela: las comunidades de aprendizaje.Barcelona: Editorial Grao, 2006. p. 19-28. 
'Dorotea Frank KERSCH

Universidade do Vale do Rio dos Sinos - UNISINOS doroteafk@unisinos.br

\section{"Renata Garcia MARQUES}

Universidade do Vale do Rio dos Sinos - UNISINOS

re.garciamarques@hotmail.com

Recebido em 01/07/2015

Aceito em 02/08/2015 